\title{
Ultrastructure of erythrocytic virus of the South African anuran Ptychadena anchietae
}

\author{
A. P. Alves de Matos ${ }^{1}$, I. Paperna ${ }^{2}$ \\ ${ }^{1}$ Electron Microscopy Unit, Pathologic Anatomy Department, Curry Cabral Infectious Diseases Hospital, R. da Beneficencia ${ }^{*}$ \\ and Functional Biology and Developmental Section of the Department of Zoology and Anthropology, Lisbon University, \\ P-1000 Lisbon, Portugal \\ ${ }^{2}$ Department of Animal Sciences, Faculty of Agriculture of the Hebrew University of Jerusalem, Rehovot 76-100, Israel
}

\begin{abstract}
Electron microscopic study of virus infections in the erythrocytes of the frog Ptychadena anchietae from northern Transvaal, South Africa revealed icosahedral iridovirus-like particles measuring 175 to $198 \mathrm{~nm}$ in diameter, containing a dense, pleomorphic nucleoid. Virions were enveloped by 2 membranes, and may be associated with extensive membranous clots. The virus assembled in the cytoplasm within spherical fibrillar virosomes. Infected cells contained a large crystalloid inclusion body in their cytoplasm and in some, the inclusion was also present in the nucleus. Infection occurred in both mature and immature erythrocytes. There was no evidence of productive infection in nonerythrocytic cells.
\end{abstract}

\section{INTRODUCTION}

Virus infections of the erythrocytes of amphibians and reptiles were previously thought to be caused by protozoan parasites and were named Toddia and Pirhemocyton.

Toddia has been found mainly in amphibians (Johnston 1975), but also in snakes (Marquardt \& Yaeger 1967) and fish (Arcay de Peraza \& McLure 1971). It is characterized at the light microscopic level by the presence of a cytoplasmic purple corpuscle representing the viral factory or virosome, and a crystalloid inclusion of unknown significance (Sousa \& Weigl 1976, Paperna \& Alves de Matos 1993).

Electron microscopic (EM) studies have shown these infections to be caused by iridovirus-like viruses (Stehbens \& Johnston 1966, Sousa \& Weigl 1976, Speare et al. 1991, Alves de Matos \& Paperna 1993).

Another potentially related intraerythrocytic iridovirus-like infection is the viral erythrocytic necrosis (VEN) of marine fish (Smail 1982).

\footnotetext{
- Address for correspondence
}

Here, we present an EM study of virus-infected erythrocytes from the frog Ptychadena anchietae, captured in Transvaal (South Africa). The infection has not been previously reported, either in this species or in southern Africa.

\section{MATERIALS AND METHODS}

Study material was obtained from the South African anuran Ptychadena anchietae (Bocage, 1867) collected in Hoedspruit, northeast Transvaal, South Africa.

Blood was collected from a clipped toe in a glass capillary tube, allowed to coagulate and then extracted into $2.5 \%$ glutaraldehyde in $0.1 \mathrm{M}$ cacodylate buffer $\left(\mathrm{pH} \mathrm{7.4)}\right.$ for fixation for $24 \mathrm{~h}$ at $4{ }^{\circ} \mathrm{C}$. Blood vessel, lung and liver pieces were also fixed as above. The material was post-fixed in $1 \%$ osmium tetroxide in the same buffer for $1 \mathrm{~h}$. After rinsing in the cacodylate buffer the material was serially dehydrated in graded ethanols and embedded in Epon. Thin sections cut on an LKB III microtome with a diamond or glass knife were stained on grid with uranyl acetate and lead citrate, and examined with a Phillips CM10 or JEOL 100S transmission electron microscope. 

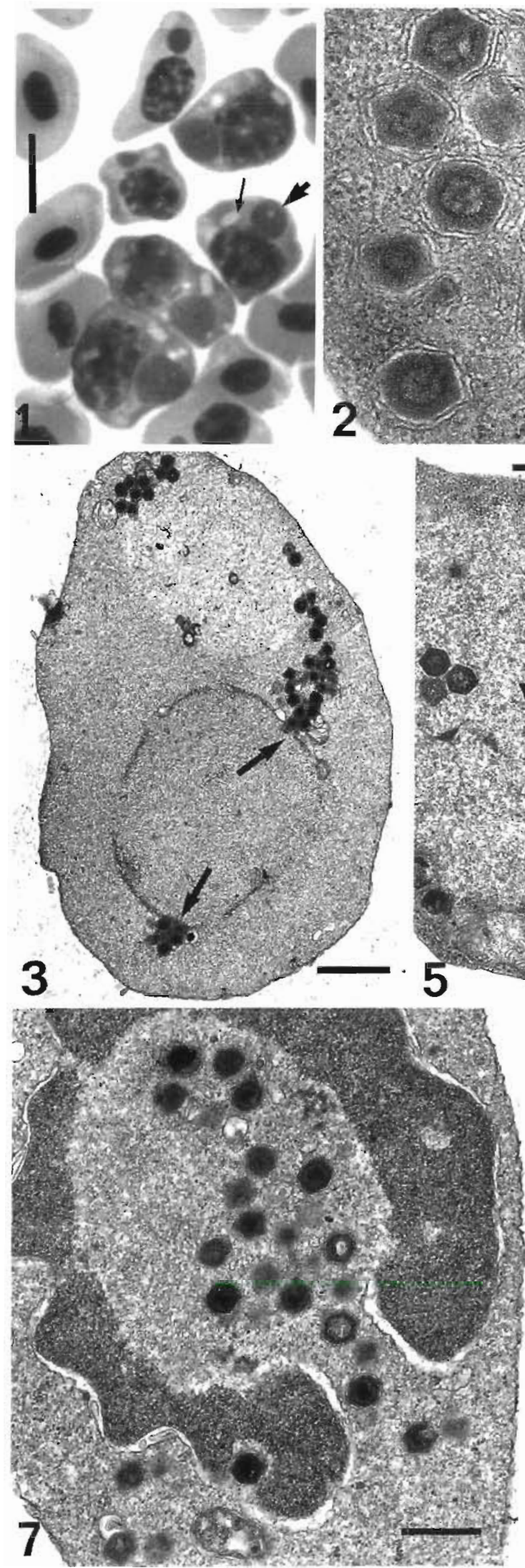
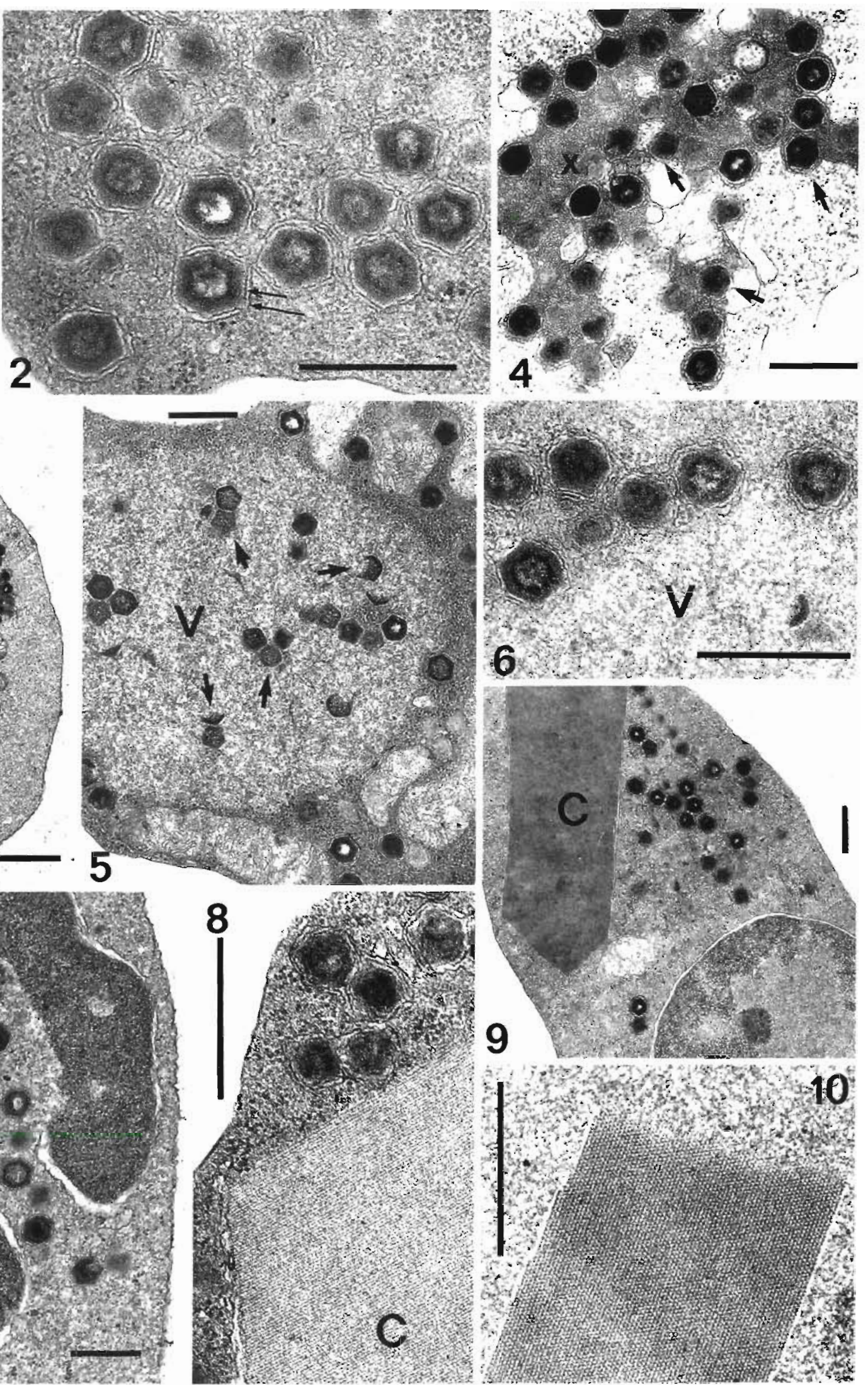


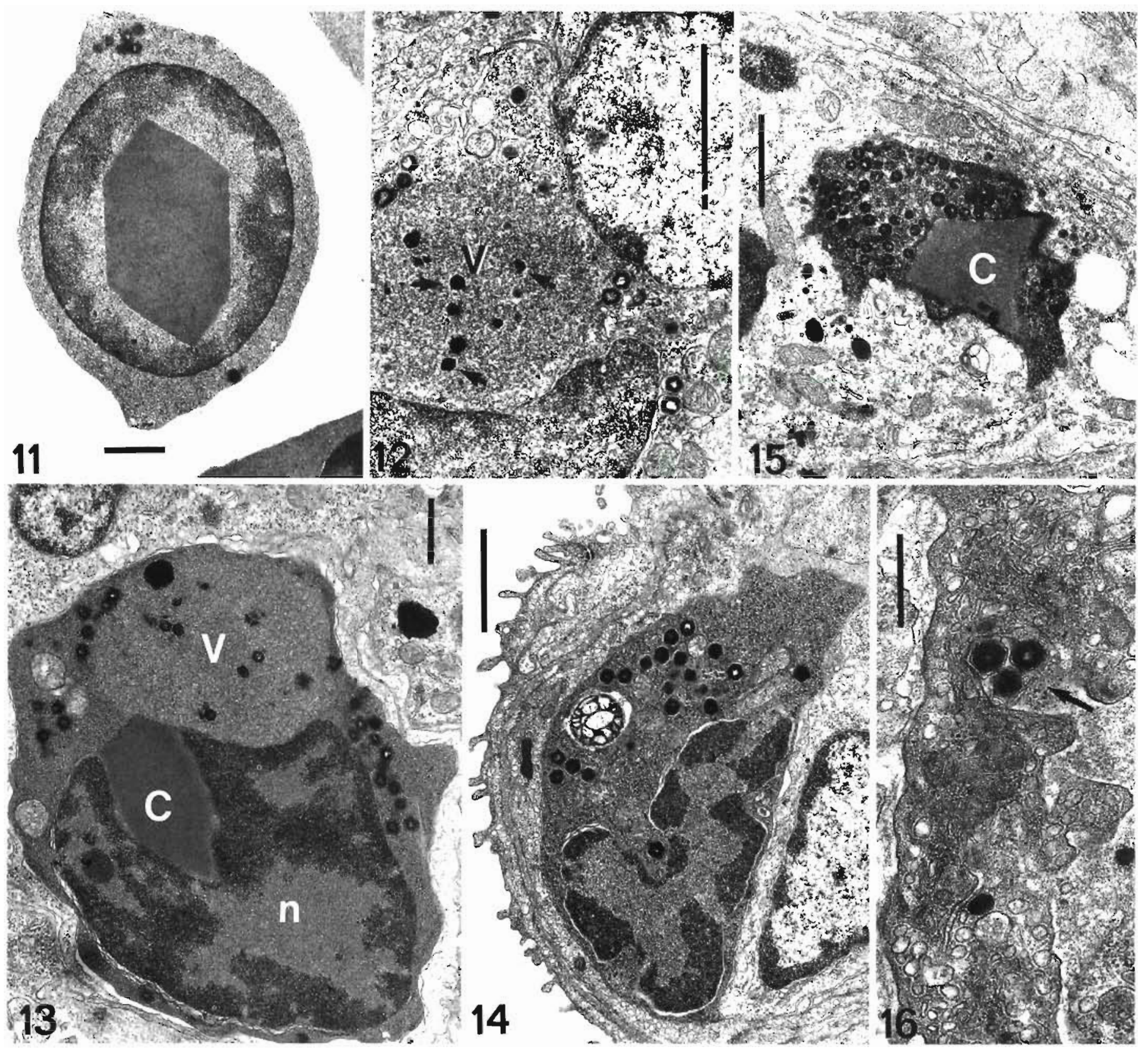

Figs. 11 to 16. Virus-infected Ptychadena anchretae Fig 11. Intranuclear crystallold body Scale bar $=1 \mu \mathrm{m}$ Fig 12 Infected spleen pro-erythroblast with a distinct virosome (V) and assembling virions (arrows) Scale bar $=2 \mu \mathrm{m}$ Fig. 13. Infected erythroblast from the spleen showing virosome $(V)$, crystallold body $(C)$ and virions (arrows); $n \cdot$ nucleus Scale bar $=1 \mu \mathrm{m} F$ Infected erythroblast from the lung. Scale bar $=2 \mu \mathrm{m}$. Fig 15 . Infected erythrocyte with crystallold body (C) phagocytized by a macrophage. Scale bar $=2 \mu \mathrm{m}$. Fig. 16 Membrane-associated vinons (arrow) within pulmonary capillaries Scale bar $=05 \mu \mathrm{m}$

Figs. 1 to 10. Virus-infected Ptychadena anchietae. Fig. 1 Light microscopic view of Giemsa staned blood smear. Bold arrow virosome; fine arrow: crystalloid. Scale bar $=10 \overline{\mu \mathrm{m}}$ Fig 2 Virions enveloped by 2 membranes (arrows) Scale bar $0.5 \mu \mathrm{m}$. Fig. 3. Damaged cell with membranous clots associated with the nuclea membrane (arrows) Scale bar $=1 \mu \mathrm{m}$ Fig. 4. Enlarged view of the membranous clot $(\mathrm{x})$ and of virions (arrow) Scale bar $=0.5 \mu \mathrm{m}$ Fig. 5. Virosomes (V) with assembling virions (arrows). Scale bar $=0.5 \mu \mathrm{m}$. Fig. 6 Enlarged view of the virosome (V) periphery. Scale bai $=05 \mu \mathrm{m}$ Fig. 7 . Virions entering the nucleus. Scale bar $=0.5 \mu \mathrm{m}$. Figs $8 \& 9$. Intracytoplasmic crystalloıd bodies (C). Scale bars $=0.5 \mu \mathrm{m}$. Fig 10 Intranuclear crystalloid body. Scale bar $=05 \mu \mathrm{m}$. 


\section{RESULTS}

No appreciable pathological changes could be demonstrated in the infected frog. Hematological data reported elswhere (Paperna \& Alves de Matos 1993) show moderate proliferation of immature cells $(17 \%$ of the total erythrocyte count), all of which became infected (Fig. 1). Pathology could be demonstrated only at the host cell level. Infection involves major changes in the erythrocyte leading to its ultimate lysis or elimination by phagocytosis.

Virions seen in sections presented a hexagonal or pentagonal outline, compatible with an icosahedral shape (Stoltz 1971) measuring 175 to $198 \mathrm{~nm}(\mathrm{n}=10)$ in diameter. Inside the particle, a dense, pleomorphic nucleoid could be found, often with a dense band delimiting an irregularly filled or sometimes empty-appearing center (Fig. 2).

Large numbers of viral particles were found in the cytoplasm of infected, circulating erythrocytes. The cytoplasmic virions were enveloped by 2 smooth membranes (Figs. $2 \& 3$ ). In damaged cells, these enveloping membranes were seen to form clots which were tied with the nuclear membrane (Figs. $3 \& 4$ ).

The virus was assembled within spherical, fibrillar virosomes in the cytoplasm. Inside these virosomes, incomplete viral capsids, not assaciated with membranes and lacking a dense nucleoid, could be found (Figs. 5 \& 6). Intranuclear particles were sometimes observed, as well as breaks in the nuclear membrane through which the virus could enter the nucleus (Fig. 7). Budding virions were never found.

Infected cells contained large crystalloid inclusion bodies within their cytoplasm (Figs. 8 \& 9) or, more rarely, in the nucleus (Figs. $10 \& 11$ ). Infected proerythroblasts and circulating erythroblasts with viral features similar to those seen in the peripheral blood erythrocytes were found in the spleen (Figs. 12 \& 13) and in the lungs (Fig 14). Many of the cells were in the process of being phagocytized by macrophages (Fig. 15). Other cell types, such as the macrophages, were never seen to be infected.

Clusters of membrane-associated virions were found within pulmonary capillaries. These virions were being phagocytized by the latter's endothelium (Fig. 16). No evidence of productive infection was observed in lung parenchyma cells

\section{DISCUSSION}

The virus observed in the South African frog was morphologically similar to the erythrocytic virus found by Sousa \& Weigl (1976) in a Brazilian frog, but was about two-thirds of the size of the erythrocytic viruses described by Bernard et al. (1968) and Desser \& Barta (1984) from North American frogs and the virus of Bufo marinus from Costa Rica described by Speare et al. (1991). Size differences have been related to generic differences in iridoviruses of insects (Willis 1990). This suggests that frog species are infected by several different viruses, and that the differential distribution of these viruses follows biogeographic regions. Similar diversity has been found among erythrocytic viruses of fish (Smail 1982) and of reptiles (Alves de Matos \& Paperna 1993).

Pentagonal and hexagonal sectional profiles of the capsid are well-documented characteristics of several icosahedral cytoplasmic viruses, including iridoviruses (Stoltz 1971). Although Gruia-Gray et al. (1989), following biochemical and biophysical studies, suggested affinity of the frog erythrocytic virus with iridoviruses, further biochemical and genetic data must be gathered for its classification: another iridovirus-like, icosahedral cytoplasmic virus (African swine fever virus) possessing double-stranded DNA was found to differ considerably from iridoviruses, and is considered to belong to a separate family (Willis 1990).

Within the virosome, the polygonal shell was often incomplete and lacked a dense inner component. These particles probably represent developing virions and indicate the virosome to be the viral assembly site. Similar viral assembly sites have been found in other studied iridoviruses, particularly in FV3 infections. However, in several insect iridoviruses and in Lymphocystis disease virus of fish, the assembly sites have different ultrastructural characteristics (Devauchelle et al. 1985). The presence of intranuclear virions seems to be related to the entry of virions into the nucleus through breaks in the nuclear membrane, although the presence of an early intranuclear replication step of the iridovirus genome (Willis et al. 1990) could conceivably raise also the possibility of an intranuclear assembly of virions.

Virions accumulating in the cytoplasm were surrounded by 2 membranes. These probably represent endoplasmic reticulum cisternae enveloping the capsid, as suggested by Sousa \& Weigl (1976). The association of the membranes with the nuclear envelope was evident in lysing cells and supports this hypothesis. Similar membranes have been reported in the other studied frog erythrocyte icosahedral viruses (Bernard et al. 1968, Gruia-Gray et al. 1989). Bernard et al. (1968) suggested these membranes to represent the residual reorientation of endoplasmic reticulum from juvenile erythrocytes in hematopoietic zones, which had not been resorbed during maturation of the infected cell. The infected, immature erythrocytes observed in this study already possessed membraneenclosed virions. Since the capsid unit membrane 
of iridoviruses is synthesized in the virosome (Devauchelle et al. 1985), the increase in the amount of cytoplasmic membranes could be related to changes in the erythrocyte, linked to the synthesis of the viral unit membranes.

Many iridoviruses leave the cell via a budding mechanism (Devauchelle et al. 1985) However, budding was not observed in this study. The association of the virions with the cytoplasmic membranes could be preventing them from reaching the cell membrane and engaging in budding. Instead, the virus seems to be released by cell lysis. Most of the circulating viruses found in lung capillaries were enclosed in membrane clots similar to those found in lysing cells.

The crystalloid body is characteristic of erythrocytic virus infections of frogs and clearly distinguishes them from the erythrocytic iridovirus-like infections in saurian reptiles (Alves de Matos \& Paperna 1993) and fish (Smail 1982). The crystalloid body was distinctly striated, suggesting a proteinaceous composition, which is different from the structure of the 'vacuoles' in saurian reptile infections, as reported by Stehbens \& Johnston (1966) and also from our own observations (Alves de Matos \& Paperna 1993). However the significance of this feature is unclear, since it remains to be determined if the crystalloid body consists of virally coded material (probably protein) or host-dependent material.

No clinico-pathological changes except for cytological damage as direct consequence of viral activity in the infected cell were so far demonstrated in any of the reported erythrocytic viral infections of frogs (Bernard 1968, Sousa 1976, Desser 1984, Speare 1991, Paperna \& Alves de Matos 1993). This contrasts with the extreme anemia characteristic of erythrocytic viral infections in saurian reptiles (Paperna \& Alves de Matos 1993).

In this study we could find no evidence of infected cells other than erythrocytic cells, thereby excluding a potential relationship with non-erythrocytic frog iridoviruses. Infected erythrocytic cells at different stages of maturation were found in the spleen. Spleen macrophages were active in the phagocytosis of infected cells, and are therefore probably important for their removal and the animal's recovery (Paperna \& Alves de Matos unpubl.). Another possible mechanism of viral elimination is the phagocytosis of virions by pulmonary endothelial cells.

Acknowledgements. The authors thank Prof. Eduardo Crespo of the Department of Zoology and Anthropology, Lisbon University, and Dr Celeste Campos of the Pathologic
Anatomy Department, Curry Cabral Infectious Diseases Hospital, for their help and support. Thanks also to Dr Moura Nunes of the Cancer Institute. Lisbon, for providing technical facilities. Collection and preparation of material for electron microscopy in South Africa was carried out during I. P.'s CSIRsponsored visit to the Zoology and Entomology Department of the Orange Free State University, Bloemfontein

\section{LITERATURE CITED}

Alves de Matos, A. P., Paperna, I. (1993). Ultrastructural study of Pirhemocyton virus in lizard erythrocytes. Annls Parasitol. hum. comp. 68: 24-33

Arcay de Peraza, L., McLure, M. T (1971). The 'Paranuclear corpuscules' in poikilothermal vertebrates. II. Description of a new species of Toddia in Electrophorus electricus (electric eel), with an expansion of the key to the species of the genus Toddia in poikilothermal vertebrates. Acta biol. venez. 7: 201-209

Bernard, G. W., Cooper, E. L., Mandell, M. L. (1968), Lamellar membrane encircled viruses in the erythrocytes of Rana pipiens. J. Ultrastruct. Res. 26: 8-16

Desser, S. S., Barta, J. R. (1984). An intraerythrocytic virus and rickettsia of frogs from Algonquin Park, Ontario. Can. J Zool. 62: 1521-1524

Devauchelle, G., Stoltz, D. B., Darcy-Tripier, F. (1985) Comparative ultrastructure of Iridoviridae. In: Willis, D. B (ed.) Iridoviridae. Springer-Verlag, Berlin, p. 1-21

Gruia-Gray, J., Petric, M., Desser, S. (1989). Ultrastructural, biochemical and biophysical properties of an erythrocytic virus of frogs from Ontario, Canada. J. Wildl. Dis. 25: 497-506

Johnston, M. R. L. (1975). Distribution of Pirhemocyton Chatton \& Blanc and other, possibly related, infections of poikilotherms. J. Protozool. 22: 529-535

Marquardt, W. C., Yaeger, R. G. (1967). The structure and taxonomic status of Toddia from the cottonmouth snake Agkistrodon piscivorus leucostoma. J. Protozool. 14: $726-731$

Paperna, I., Alves de Matos, A. P. (1993). Erythrocytic viral infections of lizards and frogs: new hosts, geographical locations and description of the infection process. Annls Parasitol. hum comp. 68: 11-23

Smail, D. A. (1982). Viral erythrocytic necrosis in fish: a review. Proc. R. Soc. Edinb. 81: 169-176

Sousa, M. A., Weigl, D. R. (1976). The vira] nature of Toddia Franca, 1912. Memorias Inst. Oswaldo Cruz 74: 213-230

Speare, R., Freeland, W. J., Bolton, S. J (1991). A possible iridovirus infection in erythrocytes of Bufo marinus in Costa Rica. J. Wildl. Dis. 27: 457-462

Stehbens, W. E., Johnston, M. R. L. (1966). The viral nature of Pirhemocyton tarentolae. J. Ultrastruct. Res. 15: 543-554

Stoltz, D. B. (1971). The structure of icosahedral cytoplasmic deoxyriboviruses. J. Ultrastruct. Res. 37: 219-239

Willis, D. B. (1990). Taxonomy of iridoviruses. In: Darai, G. (ed.) Molecular biology of iridoviruses. Kluwer Academic Publ, Boston, p. 1-12

Willis, D. B., Thompson, J. P., Beckman, W. (1990) Transcription of frog virus 3. In: Darai, G. (ed.) Molecular biology of iridoviruses. Kluwer Academic Publ., Boston, p. $173-186$

Manuscript first received: September 22, 1992

Revised version accepted: March 6, 1993 